\title{
4 \\ Rural Women Walking and Waiting
}

Managing poverty can be very time-consuming.

RUTH LISTER, POVERTY, 2004

People living in the most rural parts of Peru do a lot of walking and a lot of waiting. They walk to their terrenos (plots), to the health clinic, to school, and to the market. They will walk all day to visit family in another village. Many of the rural families that I spent time with in this study thought it was funny when I could walk some of these distances with them. They would tell one another "iElla puede caminar!" (She can walk!) with an equal mix of bemusement and pleasure. Rural Peruvians also do a lot of waiting. They wait for combis (private minibuses), for attention from bureaucrats, and for politicians to fulfill promises. They wait for the state to build roads, install sewers, provide potable water, extend electricity service to houses, send more doctors, and contract more teachers. They wait for the economic prosperity from the boom they've been hearing about to trickle down into their pockets, too. In unevenly developed places like Peru, walking and waiting are features of rural people's daily lives.

I began to grasp the significance of walking and waiting for cash during a crisp, achingly blue-skied day on the cusp of the rainy season. I was accompanying a Juntos local manager to a meeting he had called with mothers in a village called Colmica in the district of Labaconas. Colmica was not reachable by road, and the local manager had borrowed a dirt bike from the municipal government to get there. We traveled up rugged dirt paths, and when the course became steep, I would dismount and the local manager would gun the engine to jolt up the hill. After about an hour the bike was no longer able to make the climb, so we continued on foot through grasshopper-green pastures and the kind of crisp skylines achieved only when the oxygen is that thin (figure 6). Our (partially motorized) journey from the district capital to Colmica's village hall took approximately two and a half 


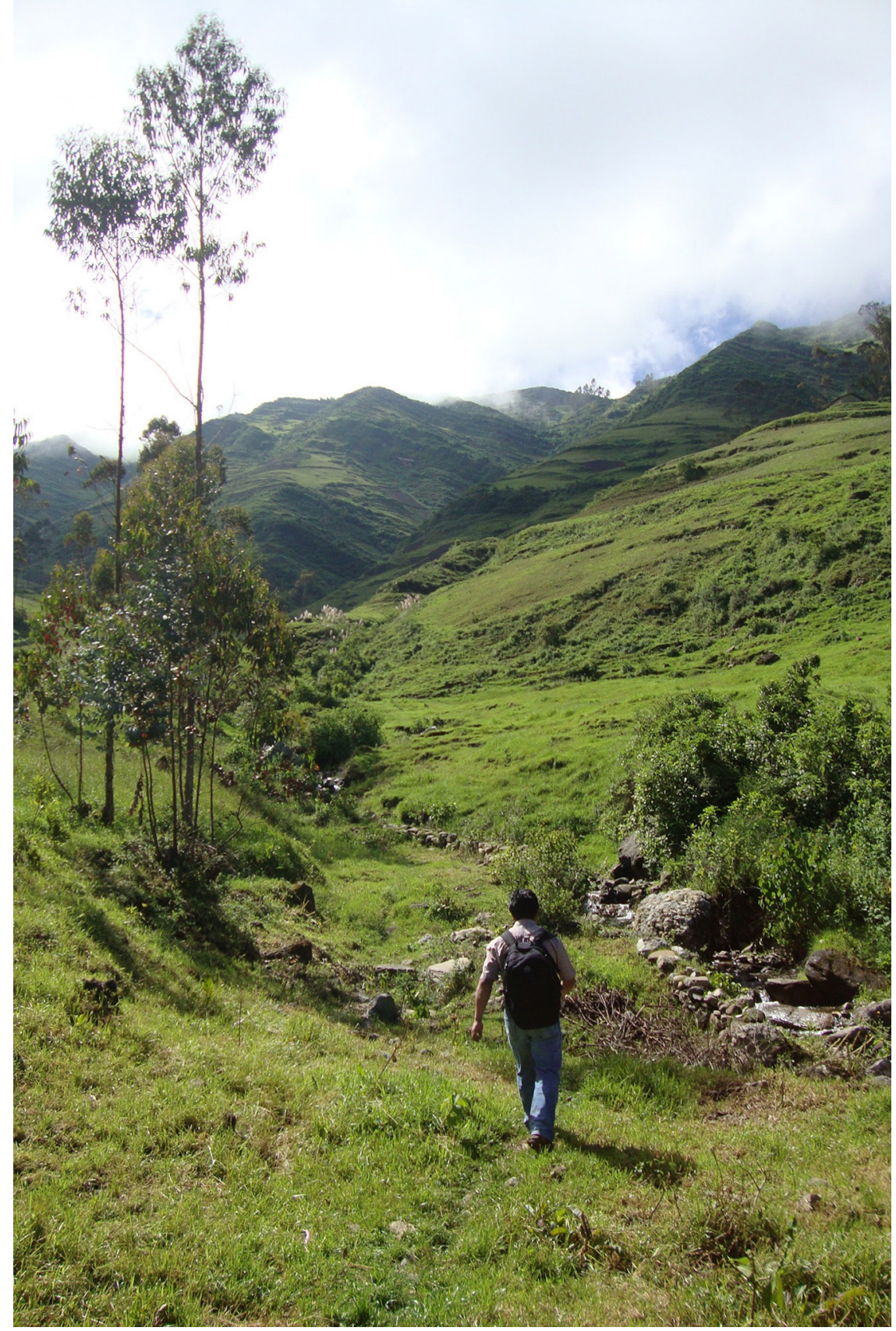

FIGURE 6. Local manager Paulino ascends the hill on foot. Photo by the author. 


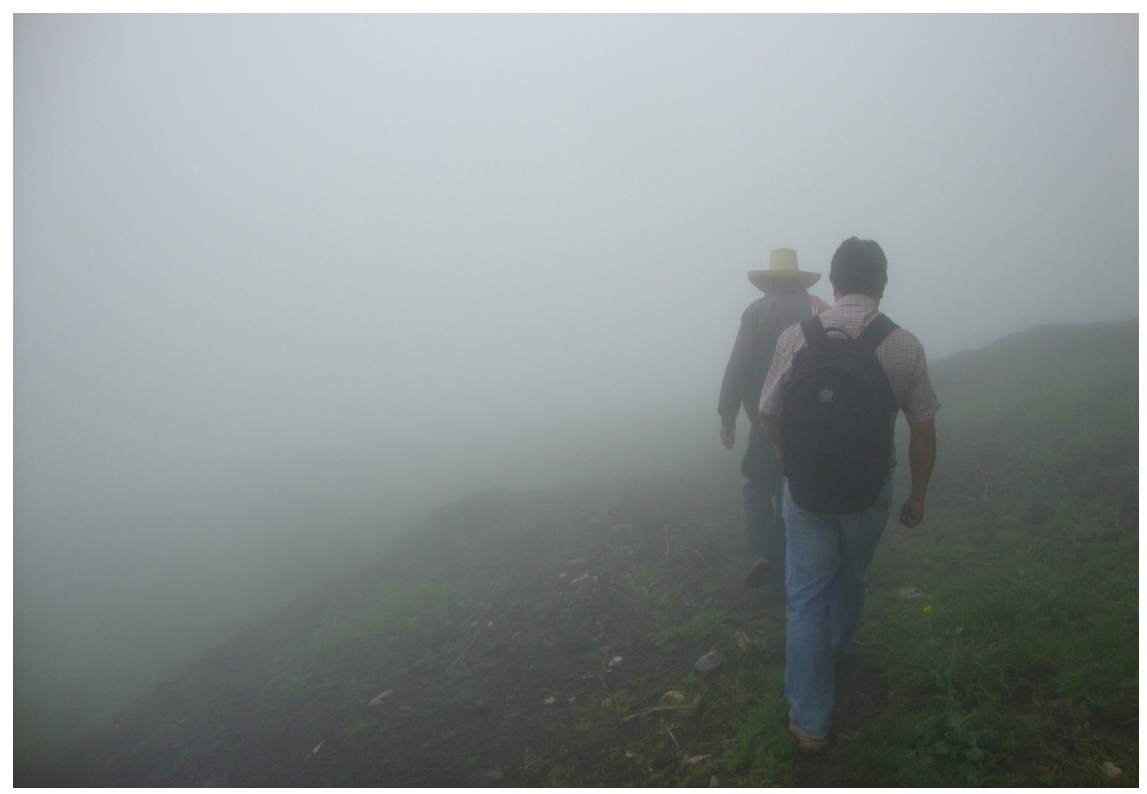

FIGURE 7. A sudden and dense seasonal fog. Photo by the author.

hours. The meeting itself lasted just shy of three hours. At its close, the local manager and I exited the small, electricity-less community building into a fog so dense it was impossible to see three feet ahead. The mountains, the district capital below, and the house a short way down the hill had all disappeared, entirely whitewashed by the weather. The fog was disorienting. It had become impossible for the local manager and me to successfully (not to mention safely) make our way down the mountain on our own. Cliffs, streams, and animals were unidentifiable until you were already upon them. The teniente (village lieutenant, or elected chief) offered to lead us. I recall at one point stumbling into the path of a large bull, whose presence and proximity I was made aware of only through its arresting moo (figure 7 ).

The environment and its propensity to change at a moment's notice shaped rural women's experiences of earning and collecting a cash incentive. The mothers who attended the meeting also returned home in the fog. Had the fog descended before the meeting, the women's attendance would still have been required.

Part of the appeal of CCTs as a method for reducing poverty is their alleged efficiency. With the use of a simple cash incentive, poor people change their behavior. Yet in practice, conditionality introduces hidden costs that are not accounted for by this simple equation. We have established that Juntos's impact evaluations did not capture information about the poor quality of the health and education services, or about what it took for women to meet program conditions in the context of uneven development. If we were to view CCTs from the perspective of women, 
would we still find them to be efficient? There are a number of long-standing feminist insights about poverty and time that have recently gained more mainstream attention, and these are worth exploring here. Women experience "time poverty" at a rate much higher than men (Antonopoulos and Hirway 2010). This is largely because women do unpaid care work in their households and communities, in addition to paid work in the formal or informal economy. If development interventions do not take into account women's unpaid labor, they have the potential to exacerbate gendered inequities (Elson 1995). Taking these feminist insights to heart, we might ask: What are the hidden costs of imposing conditions in unevenly developed places?

To answer this question, I take to heart the conviction of feminist geographer Isabel Dyck, who insisted that we pay close attention to women's more mundane, everyday undertakings, lest women and their activities "slip into the shadows" (Dyck 2005, 234). The pages that follow shed light on two of Juntos mothers' more mundane activities: walking and waiting. Mothers traveled, mostly by foot, to meet program conditions, to ensure the local manager had the correct information, and to collect the cash incentive. While the landscapes they moved through were breathtakingly beautiful, they were steep and subject to bright sun, heavy rains, and dense fog. Juntos did not make allowances for weather conditions, transportation shortages, or conflicts of interest that made women's travel uncomfortable, onerous, or costly. Women's walking and waiting draw our attention to the gendered inefficiencies of imposing conditions on social support.

\section{WALKING AND WAITING}

On a bright morning in the northern Andean dry season, Juntos mothers who had fulfilled their coresponsibilities traveled from their respective villages to the district capital of Labaconas in order to collect the cash incentive. Juntos dispensed cash from the municipal hall because there were no banks or ATMs in Labaconas. I had arrived from Cajamarca city in a combi, which was unusually full of opportunity-seekers from the city: microentrepreneurs loaded with boxes and plastic sacks who came to hawk their wares in an impromptu market that spread throughout the plaza. ${ }^{1}$ Their presence transformed the public space: what was usually a tidy, serene square became a colorful and chaotic explosion of cooking pans and mops; men on loudspeakers selling "curative" Amazonian medicines, secondhand clothing, and cheap plastic toys; and vendors preparing fried guinea pig and ceviche (fish or snails cooked in lime juice, chilies, and onion). My field notes from the day recount that this was the scene from eight oclock in the morning until four o'clock in the afternoon:

At the far side of the bustling plaza, a few hundred campesinas, many with babies secured to their backs, stand queuing in four thick lines that stretch along both sides of the municipal hall [figure 8]. The women's white sombreros and full, black woolen 


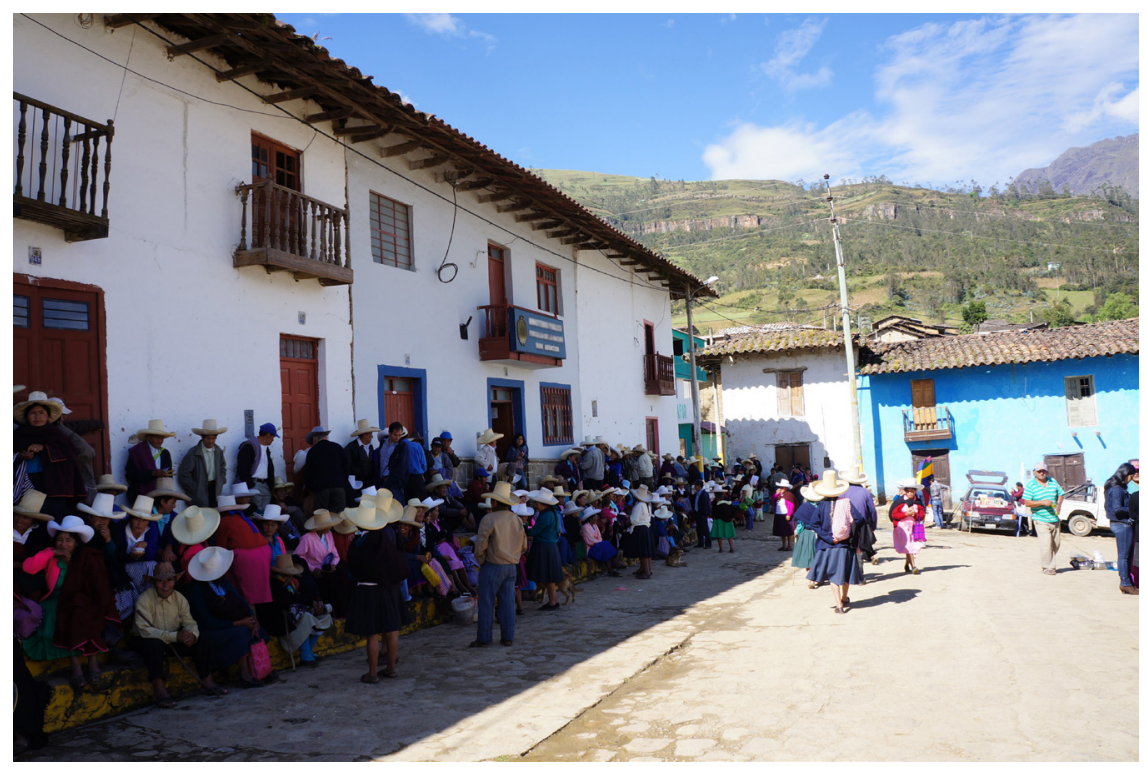

FIGURE 8. Waiting. Photo by the author.

skirts distinguish them from the handful of state and municipal employees in Western-style jeans and windproof jackets. A bright blue armored Hermes truck is parked out front, and a uniformed armed guard stands by. It carried the Juntos payments up into the mountains [figure 9]. Other than the municipal authorities, entrepreneurs, and security guards, there are very few men around. Large white posters labeled "Juntos Current Registry" are fixed to the wall on either side of the municipality doors. The registry lists the first name and surname, identity document, village, and institutional identification number of every Juntos recipient [figure 10]. The door to the municipality remains shut, and municipal employees stand guard. Local managers give queuing mothers paper tickets that will eventually allow them to enter the hall in small groups. It is hot, bright, and chaotic; every time a group of mothers is allowed through the doors, there is a lot of pushing and shoving, and the local managers yell: "Understand! There is nowhere to sit!" and "Get in line!" The queues are patrolled by a vigilant female municipal worker in Western dress who informs local managers when she notices a mother cut in line. As they enter the building, mothers are filmed by a male security guard who points the camera at them and tells them to remove their sombreros.

At this point, mothers tell me that they have been queuing for hours. Many women traveled to the capital in groups of three to five, several neighbors together. One group of women from Chan Chan left their village at 5 P.M. the previous day; they walked for four hours and spent the night in front of the municipal hall. One Juntos mother, called Aurelia, says that they have to come the day before because, with the time spent queuing, they couldn't make the trip in a single day. Other women left their communities at 3 A.M. to arrive at 6 A.M., or left at 2 A.M. to arrive at 5 A.M. 


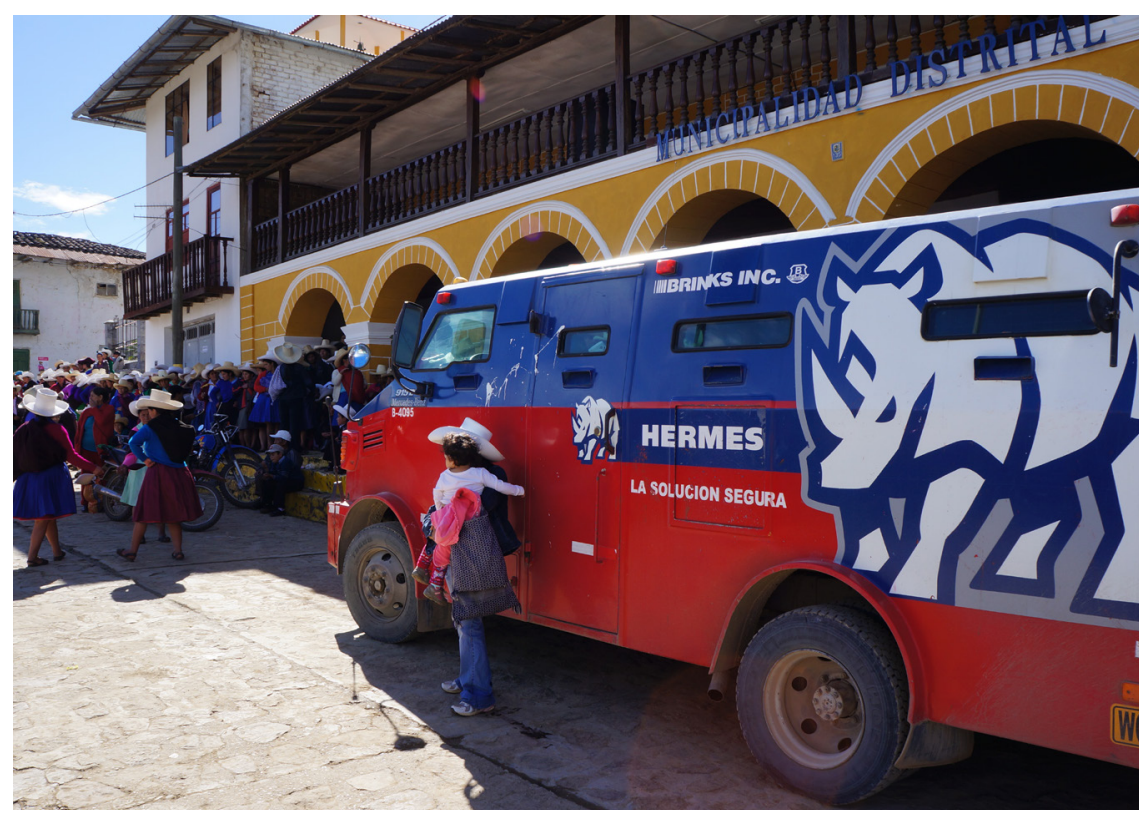

FIGURE 9. The district square on "payday." Photo by the author.

A young mother named Cenobia, her infant wrapped around her back with a colored shawl, says the mothers are unhappy because the women who live closer arrive late and cut in, while Cenobia and her neighbors "form a line but then are the last to collect." Other mothers are chastised by the local manager, who is circulating through the queues telling mothers not to let others cut in, that they should defend themselves. Cenobia, among others, protests that it is not their fault; there should be help to prevent this. The local manager responds that there are only two local managers for a thousand women, and furthermore, that the armored truck employees want to leave because the mothers are blocking the entrance to the municipal hall. The local manager threatens to take photos of the mothers who do this, saying that they'll be kicked out of the program and the photos will serve as proof of why-and if they don't queue nicely, the payment will be every three months instead, and then every six. A mother named Flor approaches with an infant on her back and produces a photocopy of a birth certificate; the local manager accepts it but tells her it is too late for her to collect the payment now; it will have to be for next month.

Halfway down the queue, five mothers huddle together; they tell me that after collecting the transfer they will make the three-hour walk to their village, where "we left our children!" Gladys says that she is tired, and they all laugh when I ask if they will rest once they return home. This time the payment took place on Friday and not Sunday, and they asked me, "Why would that be?" The sun is at full peak now, and it is less comfortable to be outside. A group of six mothers who left their village at 1 A.M. complained that "[the local manager] doesn't take into consideration that 


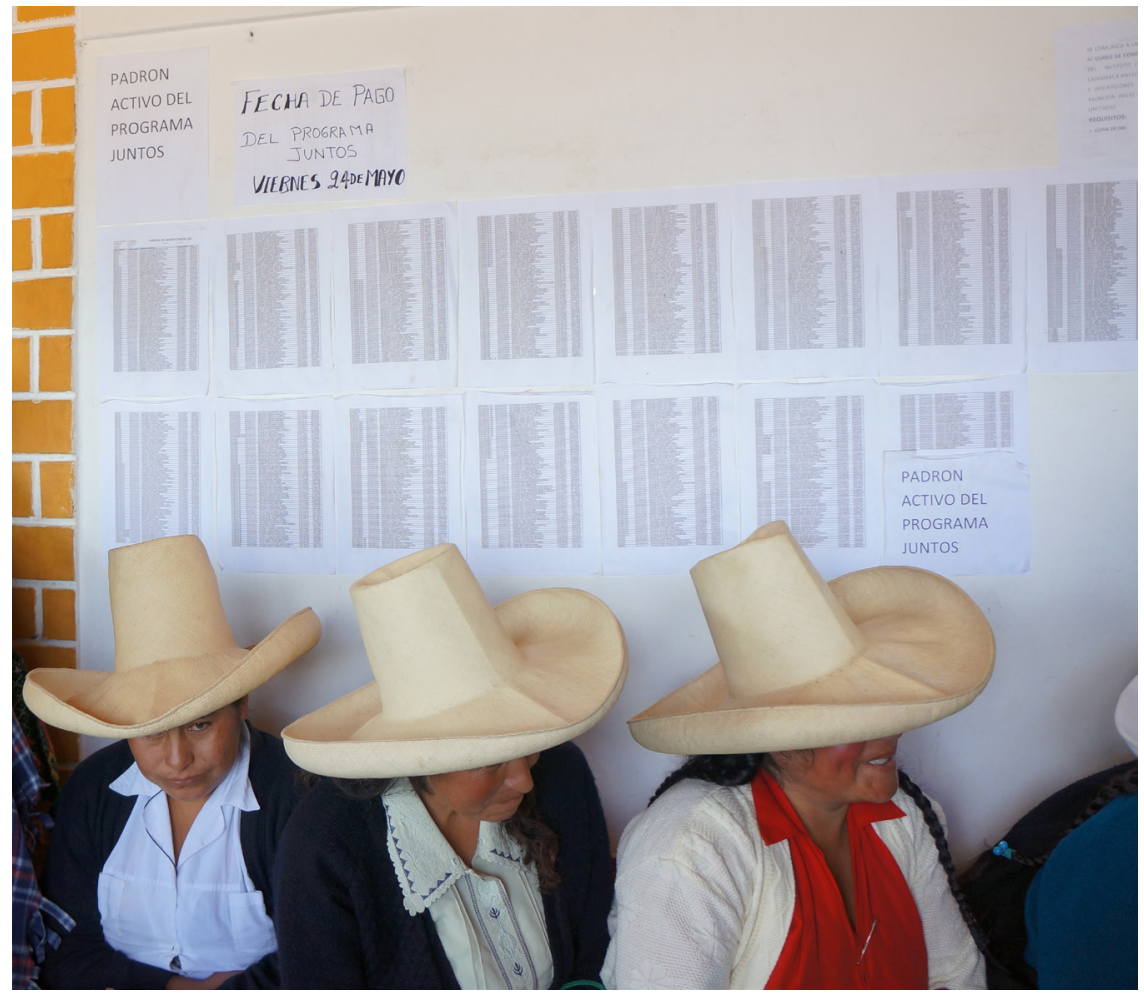

FIGURE 10. The list of compliant mothers on public display. Photo by the author.

we have our babies, it is hot out, and there is no shade." They've also left their other children at home, and their husbands are working in the fields. Sara tells me that her father is very old and she has left him alone with no one to care for him. A quarrel erupts behind us over who has cut in line.

Inside the municipal hall there are more queues. Here, mothers stand in orderly lines to collect their payment from four uniformed cashiers, who are seated at a long table set out at one end of the room and flanked by armed guards. Inside it is cool, quiet, and organized - a sharp contrast to the heat and chaos on the other side of the doors. Collecting the money is all done manually, not electronically. When signaled, a mother approaches the desk, and a cashier takes a paper receipt with the mother's name on it from a book and hands over four fifty-sole notes, or the equivalent sum in twenties. Mothers must have their national identity document with them; an armored truck employee periodically calls out to all of the women to have their ID in hand. If he doesn't see it, he inquires brusquely: "Where is it? Have it ready." A woman called Sidra has forgotten hers, and the cashier doesn't allow her to collect the payment. I wonder how long she had to walk, only to be turned away; returning to where she'd come from to retrieve her ID seems to be an unlikely option. Once the women collect the cash, they tuck it into their skirts and exit through the doors back outside. 
The way women travel and the queuing required of them reveal the starkly gendered dimensions of mobility and access to state services (Massey 1994; Radcliffe 2015). On Juntos paydays across the country, thousands of women's bodies re-pattern the Andean hills and Amazonian valleys, spilling out of households and pastures, traversing footpaths, windy roads, and rivers, ultimately concentrating into queues that spread from cash points like spiny fingers from a hand. This systematic movement of female bodies illustrates how Juntos "disciplined" (Foucault et al. 1991) women's mobility, requiring mothers to be physically present in some places rather than others and making them navigate the landscapes in between. Juntos disciplined women's movements so that they arrived at the places experts thought they should be, but it did not facilitate their ease of arrival. Women walked because the state did not provide poor, rural people with public transit, and women walked at night because the journey was so long that they could not arrive on time otherwise.

The scene at payday illustrated both the walking that women were required to do, and the waiting that was sandwiched between journeys. In order to receive the cash incentive, many of the women queued for half a day after beginning their walk before dawn or even the night before. Queuing is an exceptionally banal thing to have to do, but it is not inconsequential. Drawing on an extensive ethnography of poor people's waiting in the welfare offices of Buenos Aires, Argentina, anthropologist Javier Auyero (2012) writes about queuing as a mechanism for the production and reproduction of unequal power relations. He contends that welfare recipients learn their subordinate social position through waiting for welfare benefits. In part, this is because welfare recipients are subject to the desires and whims of low-level state bureaucrats who have more power than they do. If poor people want government assistance, they must wait patiently for the state bureaucrat to facilitate it. As a result, in the hours and hours of waiting for services, mostly without complaint, welfare recipients learn to be "patients of the state."

Through Juntos, the state shaped gendered patients-women who were responsible for their children's poverty and, therefore, responsible for waiting. To be sure, most CCT programs' gendered policy preference for female recipients could generate empowering-albeit unintended-impacts at the household level. ${ }^{2}$ However, contrary to much mainstream thinking about development, giving women cash does not automatically empower them (Chant and Sweetman 2012). For the mothers who walk and wait for Juntos, the cash comes with significant demands on the women's time and mobility. It also requires them to confront their subordinate social status in a very public way. As researchers have noted in other countries where women queue to receive cash transfers, waiting can produce feelings of shame and humiliation for the CCT recipients whose poverty is on display (see Balen forthcoming).

Whether or not waiting has empowering or disempowering effects is influenced by the spaces in which it takes place (Auyero 2012). The municipal hall and surrounding plaza where people received their payments were parsed into spaces 
of unequal access for the mothers waiting and for the actors managing women's waiting. While women waited, they were exposed to the natural elements. ${ }^{3}$ On this particular day it was bright and hot. During wet season it was cold and rained so hard that roads became impassable. Being patient meant watching urban professionals move freely to access basic comforts. These more powerful actors (local managers, security guards, municipal authorities, National Bank cashiers, myself), identifiable by uniforms and Western dress, could come and go in and out of the municipal hall, seeking a seat, a toilet, shade, and respite from the noise and jostling. The hundreds of campesinas queuing for the cash incentive were denied this option. The local managers, municipal workers, and employees of the armored truck company barred Juntos recipients' entry to the municipal hall except when it was their turn to collect the transfer. As a result, the mothers queued without access to toilet facilities, seating, or shade. The armored guard and his camera helped the local managers discipline women's behavior. When uncomfortable mothers began to wait impatiently, local managers used threats of suspension that would be backed by video surveillance.

Women queue for so long in part because Juntos is implemented in rural areas largely devoid of banking infrastructure. As a result the state goes to great (and admittedly admirable) lengths to ensure that the cash transfers reach their intended recipients. This includes armored trucks summiting Andean mountain roads, boats navigating Amazon River branches, and floatplanes landing in yet more isolated communities. Owing to the increase in demand for financial services generated by Juntos, the National Bank was opening new branches and installing ATMs in previously unserviced places, and Juntos was gradually switching over to automated payments. In these cases, mothers with bankcards and access to an ATM still traveled great distances to collect the transfer but could spend less time queuing. Many illiterate women continued to rely on local managers for help navigating the financial system. ${ }^{4}$ Local managers assisted women by entering pin codes to withdraw the cash, and women waited in queues for this support.

It is worth interrogating which aspects of Juntos we might associate with cash transfers in general-including unconditional cash transfers-and which aspects we should associate specifically with conditionality. The next sections more closely examine what it takes to implement the conditional aspect of Juntos, focusing specifically on the work that mothers do to ensure they receive their earned incentive.

\section{MOTHERS "MANAGING UP"}

Before payday, actors throughout Juntos had to complete a number of necessary work tasks. These tasks related to implementing conditionality. Local managers had to maintain an up-to-date Juntos database, which they referred to as el sistema (the system). A properly maintained database had the correct information about where a mother resided, how many children she had and their ages, and whether 
they were enrolled in school and, if so, in what grades. To keep the database current, the local managers collected copies of birth certificates, school enrollment and graduation certificates, and identity documents. The database was used by staff at Juntos headquarters in Lima to produce documents called verificationof-coresponsibility forms, which were used to monitor women's compliance with conditions. Every two months, staff in Lima sent these forms to regional Juntos offices. The forms arrived with women and children's names already listed under their respective villages of residence. Once the forms arrived, local managers were responsible for using them to monitor women's compliance with conditions.

The local managers traveled to clinics and schools, recording information about whether pregnant women and children had used the required services. The hope was that they had; during the month following the previous payday, the local manager spent her or his time traveling between villages reminding women of what they were required to do. Once the forms were complete, the local manager returned to the regional headquarters to input all of the information "into the system." If the local manager registered a mother's compliance in the system, her name would later appear on a printed roster of women who would be eligible to collect two hundred soles on the next payday.

From Lima, implementing conditionality could seem relatively straightforward. Juntos headquarters sends out forms, and shortly thereafter the database is updated with information about the targeted population's service usage. Yet focusing narrowly on the data the forms provide has led many analysts to gloss over the time and effort it takes on the part of mothers to comply with conditions and ensure that their compliance has been registered. From Cajamarca, implementing conditionality looked far more onerous. Local managers were responsible for managing an unwieldy number of households. In Santa Ana District, two local managers shared responsibility for 1,710 households. In Labaconas District, two others were responsible for 1,004 households. ${ }^{5}$ The majority of these households were not located in easily accessible, compact residential neighborhoods. They were dispersed across unevenly developed landscapes where transportation and modern communication technology was an infrequent luxury. As a result, it was not possible for local managers to independently maintain a current database and monitor whether program conditions had been met. Local managers required the help of the mothers they managed.

In addition to accessing health and education services, Juntos mothers were also required to "manage up" - that is, perform additional, time-burdensome tasks to ensure that local managers accomplished their monitoring work. If women did not manage up, they risked not receiving their cash incentive. The time women spent managing up subsidized the cost of implementing a conditional cash transfer in spaces of inadequate state investment. Managing up is another form of unpaid work that women do for the CCT. It is worth our attention because it would not be necessary if Juntos did not insist on monitoring women's compliance with conditions. 


\section{Managing Up at Meetings}

One way that women managed up was by attending meetings. Local managers summoned mothers to meetings in order to communicate information about paydays, availability of health and education services (e.g., if a "clinic" is downgraded to a "post" and therefore no longer staffed by a nurse), changes to program conditions (e.g., when Juntos increased the age for school attendance from fourteen years to eighteen years or graduation), and to solicit women's participation in other activities that were usually unrelated to Juntos. These meetings could be viewed as a necessary and efficient communication tool in a context where there were few other options. These households did not have computers or Internet access, so sending out mass emails was not an option. By making meetings mandatory, a local manager could communicate important information to all of the households within a surrounding village while expending only a few hours of her or his time.

Juntos's reliance on meetings looked different from the perspective of the mothers required to attend. Women in Juntos are often also beneficiaries of other social programs, and so they attend meetings on a continual basis. In addition to Juntos, women were often at meetings for the Glass of Milk (Vaso de Leche) Program, the Qali Warma National School Lunch Program, the National Cuna Más Program (an early childhood development initiative establishing community day-care centers), the Techo Propio Program (My Own House, which provided subsidized house construction), and parents' associations attached to the preschool, primary school, and high school. The Juntos meetings placed an additional demand on women's time and took them away from other responsibilities, including those that earned them an income (figure 11).

Juntos recipient Marisela lived in a simple home with a packed-earth floor in the same village she had been born in. She was a mother to four children, aged twenty, twelve, seven, and four. Her eldest, a daughter, had married straight out of secondary school and was a mother herself to a three-year-old girl, who Marisela also helped care for. Marisela had been in the Juntos program for five years. The cash incentive supplemented the modest income she generated from selling produce from her plot of land. Every day Marisela prepared lunch for the peones (farmhands) that helped her to cultivate her plot. When Juntos called a meeting that conflicted with her food preparation, Marisela felt compelled to prioritize the meeting. In interviews, Marisela, like other Juntos mothers, told me that attendance at meetings was mandatory and that local managers threated them with suspension from the program if they failed to attend. ${ }^{6}$ According to Marisela, "Well, when [the local managers] tell us there is a meeting, we have to go, because they say that they'll suspend us, which frightens us.... And sometimes we have to leave behind our chores and go, back and forth."

Local managers assured women's attendance by requiring them to use their national identity documents and a signature or fingerprint. Hermina, mother to five school-age children, explained how women's attendance at meetings was 


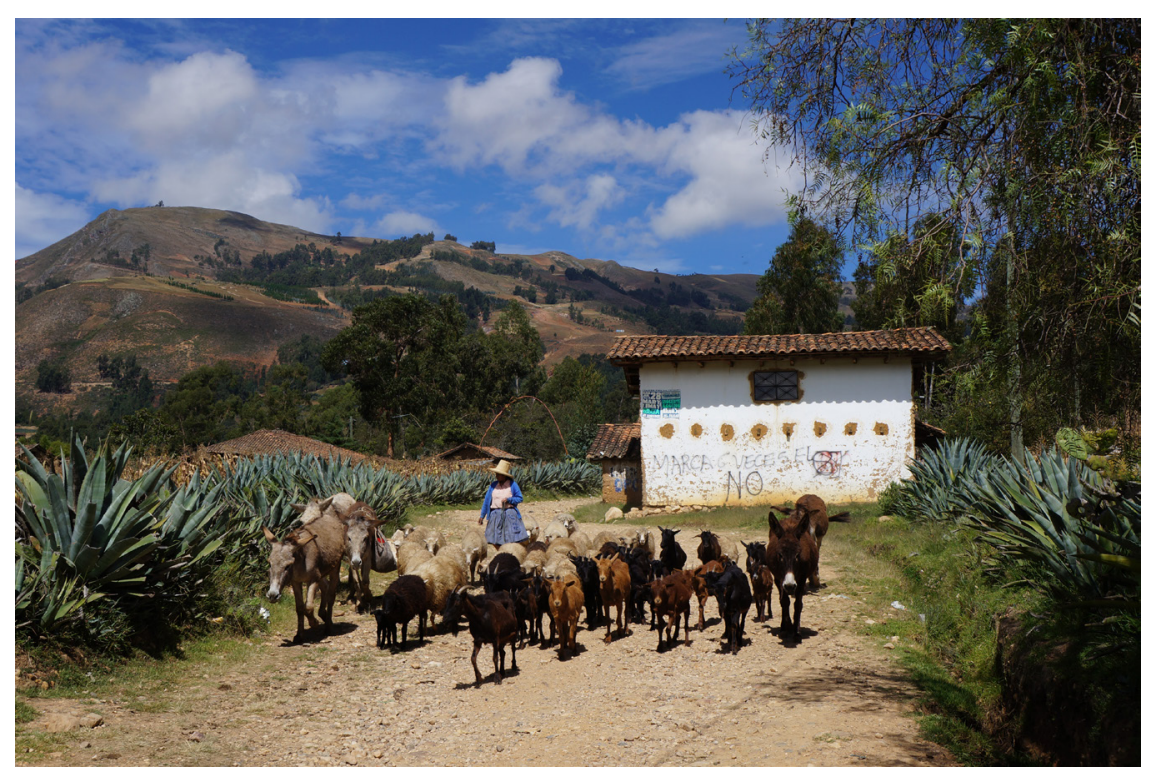

FIGURE 11. Gladys returns from taking her herd to pasture. Photo by the author.

monitored and the conditions under which this was done: "Yes, [the meeting facilitators] give [the attendance list] to the local manager, [showing] which mother participated and which mother didn't. And in the case that we miss one-well, we are excused once, but if we aren't there at two or three meetings, they punish us. . . Everything is punished if we don't do it when we are supposed to."

Asking women to sign in was a mechanism of surveillance that ensured that women spent their time in ways that helped the local manager implement conditionality. The meetings were not mandatory in any "official" sense. The verification-of-coresponsibility forms did not have a line of check boxes prompting local managers to report on whether women had attended meetings. Yet the use of surveillance techniques such as sign-in sheets bolstered the impression that the cash incentive was tied to attendance. Local managers had the power to create this impression and to enforce it. If a local manager chose to inaccurately register a mother in the system as not having met the program conditions, she or he could.

Juntos recipient Josepa lived with her two young boys in her parents' modest home on a wide brown hill in a small village in Santa Ana. Juntos meetings were held in a neighboring village down below Josepa's home, where the schools and health clinic her children attended were also located. The journey up and down the hill took about thirty minutes in each direction on foot, which is how Josepa and her young boys traveled. Josepa's eldest son was in primary school, so she made the trip at least twice daily to drop him off and pick him up. I once made 
the journey with her. We had lost track of time while eating granadillas, a delicate, pulpy fruit with a crispy orange shell, from the tree in front her house and had to rush as a result. While chuckling bemusedly, Josepa commented that I was quick (for a noncampesina, presumably), and I thought that she was being kind, rather than truthful; she would have made it down the hill in half the time had she left me with the granadillas. Whenever the Juntos local manager called a meeting, Josepa made an additional trip. She often heard about meetings at the last minute and, as a result, had to drop her other tasks and hurry down the hill:

$T C$ : Is it easy to get to the meetings?

Josepa: No! We live far away. For those who live close, well, they are right there. I have to move quickly and sometimes I'm late. Sometimes they don't tell me in advance [when there is a meeting], and then my friends come down the hill and pass the house, calling out to me, "Let's go to the meeting!” . . . Yesterday I was terribly sick with a cold, a terrible cough, and, well, I went anyway, running down the hill; and so much worse that made my cough.

Josepa's running down the hill illustrates how effectively the CCT disciplined women's behavior. When local managers called a meeting, women subordinated their own needs and interests to the whims of program staff. Evaluations of the Mexican CCT reported similar findings. There, too, cash transfer recipients described having to weigh the costs of engaging in paid labor or meeting program coresponsibilities (González de la Rocha 2006).

There was no prescribed number of meetings that local managers might call; in theory, they could call as many or as few as they would like. I was often told by local managers and other authorities from government and privately run social programs that mothers increasingly refused to attend meetings that were not called by Juntos. Local managers and the other program workers suggested that it was because attendance at Juntos meetings was attached to the cash incentive. The social program workers related this situation with resentment; their attempts at communicating information were thwarted by women's refusal to participate. As a result, they established arrangements with local managers to summon mothers to meetings under the guise of calling a Juntos program meeting. I attended one such meeting that had been called by a Juntos local manager on behalf of the Cuna Más worker, and I heard about several others. Local managers do this favor for a variety of reasons, including that they believe it is important for women to participate in the activities of the other program, or because they might need a favor in return.

To be sure, some meetings would be necessary whether the cash transfer is conditional or unconditional. At the very least, women would need to be informed about where, when, and how they could collect the payment, particularly if the cash is delivered manually. Yet many of the meetings I observed were called in 
order to align women's behavior with conditions. Yet others were used to request women's participation in activities that had little to do with the specific aims of the Juntos program (see chapter 6). The unregulated manipulation of women's time would be eliminated or at the very least reduced if Juntos were not conditional. As it stood, the current arrangement constricted women's autonomy to make their own decisions about time use in light of their own knowledge about what was best for themselves and their families.

\section{Managing Up to Demonstrate Responsibility}

In addition to attending meetings, mothers also did a great deal of work to verify that local managers had the correct information on file, to make the latter's work easier. Since policy makers typically think that local managers gather information on their own, women's work constitutes another instance of managing up. Juntos headquarters required confirmation that mothers had met the program conditions. Recall that the two local managers assigned to each of the two districts, Santa Ana and Labaconas, were responsible for managing 1,710 and 1,004 households, respectively. If each of these households had an average of three children, these local managers monitored whether 5,130 children in Santa Ana and 3,012 children in Labaconas attended health appointments or school, and whether an additional number of pregnant women attended their prenatal appointments. If the local managers failed to register this information in the system, Juntos would not release the payment.

In chapter 2, I discussed the failed agreements between Juntos and the Ministry of Health and the Ministry of Education that resulted in local managers having to complete additional paperwork. The agreements stipulated that health and education staff would fill out the Juntos verification-of-coresponsibility forms. In clinics this was supposed to occur when children and pregnant women attended the required checkups. In schools, the director or other staff person was supposed to use attendance records to fill out the Juntos forms. In practice this regularly failed to happen. According to Lina, one of the local managers: "As you've seen in Santa Ana, nobody helps you. Despite the fact that there is a signed agreement and this work is theirs to do, nothing. 'No, no, no, everyone does their own work, here are the histories,' they tell us: 'Do what you have to do, the clinic is all yours.' And they don't help us. ... They say that they have too much work; they are very busy and they don't have time."

As a result, local managers were left to track down the necessary information on their own. This amounted to a significant burden on their time. Clinics and schools were located far apart, and local managers generally faced the same lack of transportation infrastructure as the women they managed. There was also the sheer number of children and pregnant women whose appointments had to be recorded.

This additional work, and the strategies local managers devised to accomplish it, had ramifications for mothers' managing up. One common strategy I observed was 


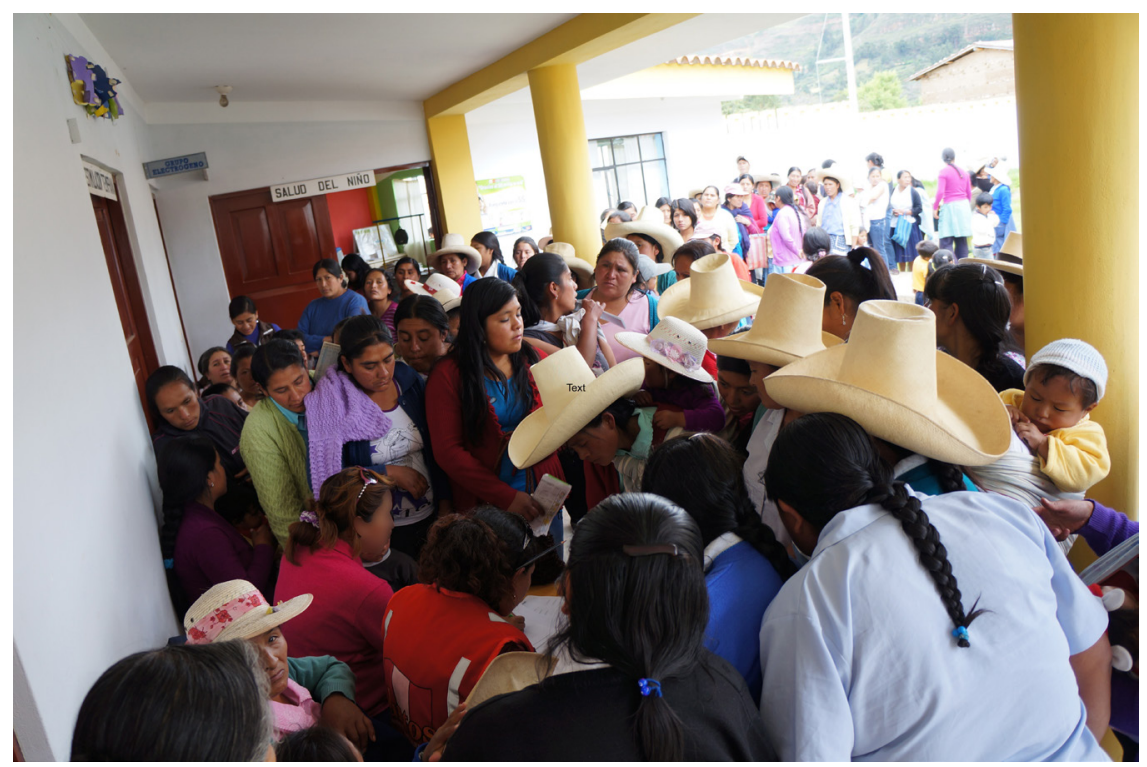

FIGURE 12. Juntos recipients "managing up." Photo by the author.

for local managers to summon women to a central health clinic or municipal office, where local managers would fill out the coresponsibility forms on the spot. Such strategies, while helping local managers meet their own professional responsibilities, wasted women's time. The following vignette describes a scenario in which mothers were required to manage up. Over the course of two and a half ten-hour days, Juntos mothers queued in the courtyard of the health clinic in the district capital of Santa Ana. Directed by their Mother Leaders, who had been instructed by the local managers, to walk down to the clinic, women collected their medical histories from inside the building and stood waiting for the two local managers to input their information into the large coresponsibility forms (figure 12).

The queues of mothers with small paper folders in hand stretch across the outdoor courtyard and spill into an unordered mass at the far end, enveloping two local managers who are seated at a desk under an awning that provides the only available shade. At 10 A.M., many women have their babies wrapped to their backs and have been on their feet for hours-the queue moves very slowly. Nearing the front third of the queue, Juntos mother Govinda tells me she has already been waiting for two and a half hours. The scene is noisy and chaotic, jostling bodies and crying babies. There is a nurse who brusquely patrols the courtyard, yelling at women to get in line and advising local managers not to attend to those who cut in.

As the local managers decipher and transfer information between forms, mothers hover around and speak all at once, holding their histories out and asking to 
be attended. Juntos mother Estrella stands in front of the desk, taking her turn. Estrella's name is not on the list for her village; the local manager asks her a series of questions to determine if she might be assigned to another village. Other mothers interrupt the questioning, asking to be attended, and the local manager pleads with them to wait their turn: "Please, listen to me!" They don't pay her any attention, and she says more forcefully: "Are you going to shut up?!” For a moment things become quieter, and the local manager makes a note of Estrella's name and village and promises to investigate later. Estrella exits the line, her program status unknown. Some of the mothers are missing information on the medical histories they present, such as their children's height and weight. These women are sent back inside the clinic to see if a staff person will fill out the health history, after which point they must get back in the queue and start again. The nurse continues to pester the women about getting in line.

It is hot, and the mothers, with their babies, stand uncomfortably in the sun. A couple of women begin to quarrel over another having cut in line; one local manager calls out, "What is going on?!" and the other yells, "Get in line! This isn't a line, it's a mob!" at which point she turns to a mother named Ynes and tells her in a flat voice that her daughter is underweight and marks a number on the form. Ynes collects her health card and disappears back into the clinic. Carla, who has been in the queue since I arrived three hours earlier, is questioned about where she currently resides; she reveals that she has moved to Cajamarca, which is not allowed (Juntos does not intervene in urban centers). The local managers consult, and one makes a "cut it" gesture with her hands to signal "no," and Carla walks away.

A baby screams, and another several start to cry. Some other women laugh. It is very loud. The nurse wants to know if the local managers will attend to the last person or if the remaining women should come back later. They say they will attend them a while longer, and the nurse says, "Yes, ok, but until what time, because the children are dying of hunger and the women want to leave and feed them." The local managers decide to attend the queue until 1 P.M., and then come back and finish at 2 P.M., leaving those women who have yet to be attended to wait. At this point there are only eight or ten mothers left.

With all of the walking and waiting, the scene at the health clinic bore striking similarities to the Juntos payday. Waiting for hours for the local manager's attention was a tedious and uncomfortable exercise for the mothers, many of whom had walked for hours to arrive there, and many others who had come with babies on their backs. At a later event at a municipal office, local managers similarly monitored women's compliance with health conditions. Rather naively, I questioned a fussing baby: "What's the matter, dear?" Her mother, Sol, turned to me and said with understandable impatience: "It is because we have been here since ten." The local manager had directed Sol to arrive at ten in the morning, which she did. However, the local manager arrived three hours late, at 1 P.M. When she arrived, she did not apologize for making the mothers wait. The local manager set straight to business: she took a seat at a desk and proceeded to summon the mothers one at a time to stand before her. She then set to transferring 
information from the medical histories the women had brought into the broad, white Juntos forms.

Some mothers waited for hours at the central clinic only to learn that the local manager had already been to their village and retrieved the information they required. As a result the mothers had waited in vain. In other cases women were unclear about which conditions they were actually required to meet. Other mothers waited, only to be informed by the local manager that they, too, had waited in vain because their children were all over five years of age (at which point Juntos monitored school attendance). In other cases, local managers informed waiting mothers that they would be suspended because their children had not attended all of the required health appointments. It was clear from the confounded expressions on the women's faces that they had been under the impression that they had done everything correctly. In such cases there were a number of possibilities for what had gone wrong. The mother may not have known or understood what was required of her to meet the health conditions (for instance, how many health appointments her children had to attend). She also may have forgotten to attend an appointment (the health clinic staff did not phone women to remind them of their appointments, a common practice in better-resourced health systems). The mother may also have delivered her children promptly to all of the required health appointments but the nurse had failed to properly record her attendance.

Sometimes women managed up because the local manager asked them to. In other cases, women managed up to make sure that the local manager had the correct information about their compliance with conditions. Juntos recipient Leocadia stood out from most of the other Juntos mothers because she wore Western dress. She arrived for our interview in trousers and a delicate colored scarf, the type that was made in a factory somewhere, rather than the tejidos women wove themselves in the villages. Leocadia was illiterate and cleaned a wealthier family's home in Cajamarca city on Saturdays to support her two children. The father of Leocadia's children was abusive. In order to escape him, Leocadia had moved her children from one village to another. In theory, Leocadia could have been expelled from Juntos for earning a salary that placed her household just above the imposed income threshold. Recognizing the risk but also needing the extra financial support the cash transfer offered single mothers, Leocadia went to great lengths to maintain her status as a Juntos recipient.

One persistent issue that Leocadia faced was that she and her children were still registered with Juntos in the village where their father resided. In addition to stipulations about income, Juntos had rules about residency and required mothers to present paperwork proving that their children were enrolled in school. Confronted with unresolved uncertainties and a complicated residency situation, Leocadia frequently sought out her local manager to make sure that her information was correctly registered "in the system" and that she would not end up erroneously suspended. I talked to Leocadia about her status. 
TC: Have you ever been suspended?

Leocadia: No, I always [do what I'm supposed to]. They haven't suspended me yet. Who knows until when? [laughs]

TC: I've been told sometimes there are errors and some women end up suspended even when they've done [what they are supposed to].

Leocadia: Yes ... sometimes [mothers] present a whole bunch of documents, and in the end it's like there was nothing at all in the system. In these cases we have to be [vigilant]. For example in my case, I collect [the transfer] in [a different village]. So I go to meetings here, but my name appears on the list over there. As I don't see or communicate with the [local manager] there, sometimes I go to find her. I go to the other village and I ask her if I'm missing anything, or if I've done something wrong. So she looks in the system and she says to me, "You are fine" or "You are missing this thing." And if I am missing something I go and bring it to her again.

Leocadia traveled three hours by foot and combi to reach the village where she was registered. The need for her to return there also meant that she might confront her abusive ex-partner. Yet as Leocadia noted, if she chose not to manage up in this way, she risked losing access to a consistent source of income that helped her meet her children's needs.

In rural Peru, moving was not an uncommon occurrence. Women migrated to find better schools for their children, to escape abusive relationships, or to seek family support after being abandoned by their spouses. Leocadia was willing to move to a new village, to live on her own, and to undertake poorly paid and often undignified domestic work in order to improve her children's opportunities. Had the cash transfer been unconditional, Leocadia would have confronted a different situation. An unconditional cash transfer would enable women like Leocadia to provide for her family in a (not uncommon) situation of violence while eliminating the need to waste her time. It would not eliminate all of her problems, but it would alleviate some of them.

Managing up involved paperwork. Retaining active status as a Juntos recipient required women to provide their local manager with photocopies of birth certificates, confirmation of school enrollment, graduation certificates, national identity documents, and "proof of residence" forms to indicate that they lived in a place that Juntos recognized as poor. Sometimes this involved a terrible runaround. The local manager could request that a mother produce a photocopy of a document that she did not have on hand; it might be at home in her village, which was located several hours away on foot. Managing up often also required women to navigate services and circumstances unfamiliar to them and to draw on resources and skills that they might not possess. During a verification of health coresponsibilities in Santa Ana, Juntos recipient Edelmira made four trips between the municipal office 
where the local manager was stationed and the photocopy shop. Each time, she returned with paperwork that did not satisfy the local manager. Like many Juntos recipients, Edelmira was illiterate and was unable to decipher what was on the paper. Edelmira paid for all of the unsatisfactory copies out of her own pocket. After the fourth trip, the local manager asked Edelmira to put the document on a USB, which is almost certainly a tool most Juntos mothers have never heard of. Edelmira's bewilderment was obvious, yet the local manager failed to acknowledge it and Edelmira left the office.

Local managers confessed to me that when mothers provided them with photocopies, the local managers often misplaced them or forgot to deal with them. Juntos recipients were not privy to what happened with their paperwork once the local manager tucked it into a backpack and returned to the city. As a result, for Juntos mothers the process of earning the cash incentive was mysterious. When their efforts to clarify or correct their program status were unfruitful, many women reported that it was as if "there was nothing at all in the system." It is little wonder that mothers like Leocadia and Sol walked and waited above and beyond what was necessary to attend health appointments and deliver their children to school. Mothers managed up because there was no other option. The enforcement and monitoring of conditionality in unevenly developed places required women to manage up. Conditionality was contingent upon women's willingness to walk and wait for stretches of time that would be unthinkable to ask of wealthier women or men in places made easier to navigate because they were better resourced.

Earlier in the chapter I suggested that in requiring women to walk and wait for social support, Juntos produced gendered patients of the state. Women's managing up illustrates that it was not only that Juntos made women patient. Managing up was a productive labor upon which Juntos relied. Women's walking and waiting were part of how local managers implemented Juntos. The women's labors were necessary in order for the state to implement a cash transfer that was conditional and tightly monitored.

This gendered labor-which was necessary from an administrative point of view-was unpaid and often demeaning. People "get a sense of [themselves]" while they wait in queues for state services (Corbridge 2007, 196). Put differently, people learn and relearn where they fit in society when they are made to wait for goods and services to which they are entitled or might simply just need. Provided they had met the program conditions, women had a right to the Juntos payment. The way that policy makers and program administrators in Lima talked about Juntos as a right trickled down to regional program staff, and some-but not manymothers also related to me that Juntos was their right. Yet the walking and waiting and the circumstances under which these activities were carried out reinforced a system that "privilege[d] rank over rights" (Corbridge 2007, 196). Walking and waiting, sometimes to receive payment, sometimes to manage up, gave women a sense of their subordinate position in relation to all of the other people with whom 
they interacted. When women's labors failed to materialize in state records-having disappeared into the ever-mysterious system-they got a sense of their subordinate position then, too. ${ }^{7}$ Women's time, needs, confusion, and dignity were of little import to the frontline state workers who came from the city to enforce the state's preferred schedule of caring and to monitor women's compliance with it.

We might say that women's walking and waiting "put them in their place." Like societies in many other parts of the world, Peruvian society is deeply hierarchical. Poor, rural campesinas occupy some of the lowest social rungs. To be sure, they occupied this position before Juntos arrived in their communities. Imposing a conditional program of social support simply reinforces their subordinate social position.

\section{CONCLUSION}

Most research on CCTs questions if the programs achieve high levels of compliance, rather than how. CCTs are not efficient when viewed from the perspective of the mothers who walk and wait for "a little bit of help" from the state. Juntos was rife with gendered inefficiencies. The time that mothers spent walking and waiting bolstered the administrative capacities of the Juntos program. This was time that could have otherwise been dedicated to subsistence farming, to assisting children with schoolwork, to weaving or cooking or helping a neighbor, to leisure. Juntos's gendered inefficiencies were made visible to me only after I accompanied women in their more mundane, everyday activities. Yet it was not only that mothers were asked to support a well-intentioned program and that their time was sacrificed, or even wasted, in the process. The wasting of women's time had the unintended consequence of putting women in their place.

This chapter could be read as evidence of failure in the implementation of an otherwise good policy. In this sense, the generalizability of my observations about managing up hangs on yet another empirical question-whether local managers' shortcomings were due to local discretion or to how the CCT was designed. It could be that mothers needed to manage up because their individual local managers were lazy or recalcitrant, or because these managers believed that the women had nothing better to do. An alternative explanation is that CCTs are designed in a way that makes it impossible for local managers to do the job that experts in Lima think they are doing. It could be that CCTs are designed in a way that relies on the unacknowledged contributions of women's unpaid labor. To examine these possible explanations, we must look at what it is that local managers are expected to do, as well as what they actually do. 